\title{
Admission fasting plasma glucose is associated with in-hospital outcomes in patients with acute coronary syndrome and diabetes: findings from the improving Care for Cardiovascular Disease in China - Acute Coronary Syndrome (CCC-ACS) project
}

Nan Ye ${ }^{1}$, Lijiao Yang ${ }^{1}$, Guoqin Wang ${ }^{1}$, Weijing Bian ${ }^{1}$, Fengbo Xu' ${ }^{1}$ Changsheng $\mathrm{Ma}^{2}$, Dong Zhao ${ }^{3}$, Jing Liư ${ }^{3}$, Yongchen $\mathrm{Hao}^{3}$, Jun Liư ${ }^{3}, \mathrm{Na} \mathrm{Yang}^{3}$, Hong Cheng ${ }^{3 *}$ (i) and on behalf of the CCC-ACS

\footnotetext{
Abstract

Background: The discrepancy between glycosylated hemoglobin ( $\mathrm{HbA}_{1 c}$ ) and fasting plasma glucose (FPG) in clinical practice may be related to factors such as acute stress, renal dysfunction, and anemia, and its relationship with in-hospital outcomes is uncertain. The aim of this study was to investigate the association between the type of discrepancy between $\mathrm{HbA}_{1 c}$ and FPG and in-hospital outcomes in patients with acute coronary syndrome (ACS) and diabetes.

Methods: The Improving Care for Cardiovascular Disease in China - Acute Coronary Syndrome (CCC-ACS) project is a national, hospital-based quality improvement project with an ongoing database. Patients with ACS, diabetes and complete $\mathrm{HbA}_{1 c}$ and FPG values at admission were included. The consistent group included patients with $\mathrm{HbA}_{1 \mathrm{c}}<6.5 \%$ and $\mathrm{FPG}<7.0 \mathrm{mmol} / \mathrm{L}$ or $\mathrm{HbA}_{1 \mathrm{c}} \geq 6.5 \%$ and $\mathrm{FPG} \geq 7.0 \mathrm{mmol} / \mathrm{L}$. The discrepancy group included patients with $\mathrm{HbA}_{1 c} \geq 6.5 \%$ and $\mathrm{FPG}<7.0 \mathrm{mmol} / \mathrm{L}$ (increased $\mathrm{HbA}_{1 c}$ group) or $\mathrm{HbA}_{1 c}<6.5 \%$ and $\mathrm{FPG} \geq 7.0$ $\mathrm{mmol} / \mathrm{L}$ (increased FBG group).

(Continued on next page)
}

\footnotetext{
* Correspondence: drchengh@163.com

${ }^{3}$ Department of Epidemiology, Beijing Anzhen Hospital, Capital Medical University, Beijing Institute of Heart, Lung and Blood Vessel Diseases, No. 2 Anzhen Street, Chao yang District, Beijing 100029, PR China

Full list of author information is available at the end of the article
}

C The Author(s). 2020, corrected publication 2021. Open Access This article is licensed under a Creative Commons Attribution 4.0 International License, which permits use, sharing, adaptation, distribution and reproduction in any medium or format, as long as you give appropriate credit to the original author(s) and the source, provide a link to the Creative Commons licence, and indicate if changes were made. The images or other third party material in this article are included in the article's Creative Commons licence, unless indicated otherwise in a credit line to the material. If material is not included in the article's Creative Commons licence and your intended use is not permitted by statutory regulation or exceeds the permitted use, you will need to obtain permission directly from the copyright holder. To view a copy of this licence, visit http://creativecommons.org/licenses/by/4.0/. The Creative Commons Public Domain Dedication waiver (http://creativecommons.org/publicdomain/zero/1.0/) applies to the data made available in this article, unless otherwise stated in a credit line to the data. 
(Continued from previous page)

Results: A total of 7762 patients were included in this study. The numbers of patients in the consistent and discrepancy groups were 5490 and 2272 respectively. In the discrepancy group, increased $\mathrm{HbA}_{1 c}$ accounted for $77.5 \%$ of discrepancies, and increased FPG accounted for $22.5 \%$ of discrepancies. After adjusting for confounders, patients in the increased FPG group had a 1.6-fold increased risk of heart failure (OR, 1.62; 95\% $\mathrm{Cl}, 1.08-2.44)$, a 1.6-fold increased risk of composite cardiovascular death and heart failure $(\mathrm{OR}, 1.63 ; 95 \% \mathrm{Cl}$, 1.09-2.43), and a 1.6-fold increased risk of composite major adverse cardiovascular and cerebrovascular events (MACCEs) and heart failure $(\mathrm{OR}, 1.56 ; 95 \% \mathrm{Cl}, 1.08-2.24)$ compared to patients in the increased HbA $\mathrm{H}_{1 c}$ group.

Conclusions: Patients with an increased FPG but normal $\mathrm{HbA}_{1 c}$ had a higher risk of in-hospital adverse outcomes than those with increased $\mathrm{HbA}_{1 c}$ but normal FPG. This result may indicate that when $\mathrm{HbA}_{1 c}$ and FPG are inconsistent in patients with ACS and diabetes, the increased FPG that may be caused by stress hyperglycemia may have a more substantial adverse effect than increased $\mathrm{HbA}_{1 \mathrm{c}}$, which may be caused by chronic hyperglycemia. These high-risk patients should be given more attention and closer monitoring in clinical practice.

Trial registry: Clinicaltrial.gov, NCT02306616. Registered 29 November 2014.

Keywords: Acute coronary syndrome, Diabetes, Fasting plasma glucose, Glycosylated hemoglobin

\section{Background}

Cardiovascular disease is the leading cause of both death and premature death in China and is the cause of $40 \%$ of deaths in the Chinese population [1]. Acute coronary syndrome (ACS) is an acute manifestation of cardiovascular disease with a high risk of mortality that can lead to critical conditions such as cardiogenic shock and cardiac arrest. Patients with ACS and diabetes usually have worse clinical outcomes than those with normal blood glucose [2-8], regardless of in-hospital or long-term outcomes. Indicators commonly used for evaluating blood glucose include intravenous blood glucose, glycosylated hemoglobin $\left(\mathrm{HbA}_{1 \mathrm{c}}\right)$, and glycosylated serum albumin. Glucose was first used in the diagnosis of diabetes, including fasting plasma glucose (FPG), oral glucose tolerance tests and random blood glucose. In 2013, the American Diabetes Association approved the use of $\mathrm{HbA}_{1 \mathrm{c}}$ to diagnose diabetes [9]. In addition to their diagnostic value, FPG and $\mathrm{HbA}_{1 \mathrm{c}}$ are also associated with clinical outcomes. Several studies have shown that abnormal blood glucose is an important factor associated with clinical outcomes in patients with ACS and diabetes [10-17].

However, the discrepancy between HbA1c and FPG can be observed in clinical practice, which has not been fully investigated until now. This condition may be related to factors such as acute stress, renal dysfunction, and anemia, which may affect FPG and $\mathrm{HbA}_{1 \mathrm{c}}$. The discrepancy can be an increased FPG with a normal $\mathrm{HbA}_{1 \mathrm{c}}$ or an increased $\mathrm{HbA}_{1 \mathrm{c}}$ with a normal FPG. We decided to explore which discrepancy indicates worse in-hospital outcomes. There are few studies focusing on this issue.

The Improving Care for Cardiovascular Disease in China - Acute Coronary Syndrome (CCC-ACS) project is a national, hospital-based quality improvement project with an ongoing database, aiming to increase adherence to ACS guidelines in China and to improve patient outcomes. We conducted this study based on the CCC-ACS project to investigate the types of discrepancies between $\mathrm{HbA}_{1 \mathrm{c}}$ and FPG and their relationships to in-hospital outcomes.

\section{Methods}

\section{Research design}

Details of the design and methodology of the CCC-ACS project have been published [18], and the study was registered at ClinicalTrials.gov (NCT02306616). In brief, the CCC-ACS is a national, hospital-based quality improvement project with an ongoing database, aiming to increase adherence to ACS guidelines in China and to improve patient outcomes. It was launched in 2014 as a collaborative initiative of the American Heart Association and the Chinese Society of Cardiology. A total of 240 hospitals were recruited, representing the diversity of ACS care in hospitals in China, including 150 tertiary hospitals in phase I and phase II and 82 secondary hospitals and 8 tertiary hospitals in phase III (from July 2017) and phase IV (from November 2018). Clinical data were collected via a web-based data collection platform (Oracle Clinical Remote Data Capture, Oracle Corporation). Trained data abstractors entered the data elements abstracted from medical charts. Eligible patients were consecutively reported to the CCC-ACS database for each month before the middle of the following month. Approximately 5\% of reported cases were randomly selected and compared with the original medical records. An audit by a third party was performed to 
ensure that cases were reported consecutively rather than selectively.

\section{Research population}

A total of 104,516 inpatients with ACS, identified based on their principal diagnosis at discharge, were enrolled from 240 hospitals across China from November 2014 to July 2019. Patients with diabetes and complete $\mathrm{HbA}_{1 \mathrm{c}}$ and FPG values at admission were included in this study. Only patients from July 2017 to December 2019 were included in this study because the FPG value at admission was not included in the database before July 2017. Patients were divided into a consistent group and a discrepancy group based on the $\mathrm{HbA}_{1 \mathrm{c}}$ and FPG values at admission. The consistent group included patients with $\mathrm{HbA}_{1 \mathrm{c}}<6.5 \%$ and $\mathrm{FPG}<7.0 \mathrm{mmol} / \mathrm{L}$ or patients with $\mathrm{HbA}_{1 \mathrm{c}} \geq 6.5 \%$ and $\mathrm{FPG} \geq 7.0 \mathrm{mmol} / \mathrm{L}$. The discrepancy group included patients with $\mathrm{HbA}_{1 \mathrm{c}} \geq 6.5 \%$ and FPG $<7.0 \mathrm{mmol} / \mathrm{L}$ or patients with $\mathrm{HbA} 1 \mathrm{c}<6.5 \%$ and $\mathrm{FPG} \geq 7.0 \mathrm{mmol} / \mathrm{L}$. The discrepancy group was further divided into an increased $\mathrm{HbA}_{1 \mathrm{c}}$ but normal FPG group $\left(\mathrm{HbA}_{1 \mathrm{c}} \geq 6.5 \%\right.$ and $\left.\mathrm{FPG}<7.0 \mathrm{mmol} / \mathrm{L}\right)$ and an increased FPG but normal $\mathrm{HbA}_{1 \mathrm{c}}$ group $\left(\mathrm{HbA}_{1 \mathrm{c}}<6.5 \%\right.$ and $\mathrm{FPG} \geq 7.0 \mathrm{mmol} / \mathrm{L}$ ). Institutional review board approval was granted for the use of an aggregate data set for research and quality improvement by the Ethics Committee of Beijing Anzhen Hospital, Capital Medical University. No informed consent was required.

\section{Definition of variables}

Diabetes was defined as having a history of diabetes, receiving glucose-lowering agents before hospitalization, having diabetes listed in the medical records as a secondary discharge diagnosis, or having $\mathrm{HbA}_{1 \mathrm{c}} \geq 6.5 \%$ at admission. Hypertension was defined as having a history of hypertension, receiving antihypertensive medication, or having systolic blood pressure $\geq 140 \mathrm{mmHg}$ or diastolic blood pressure $\geq 90 \mathrm{mmHg}$ at admission. The ACS classification was based on the primary diagnosis at discharge in the medical record. Non-ST-segment elevation ACS was defined as non-ST-segment elevation myocardial infarction (STEMI) or unstable angina. All the laboratory testing values were the values tested the first time after admission. The estimated glomerular filtration rate (eGFR) was calculated according to the equation developed by the Chronic Kidney Disease Epidemiology Collaboration [19]. Medication was prescribed after admission.

\section{In-hospital outcomes}

The outcomes of this study included major adverse cardiovascular and cerebrovascular events (MACCEs), heart failure, composite of cardiovascular death and heart failure, composite of MACCEs and heart failure, and death from any cause. MACCEs were defined as cardiovascular death, cardiac arrest, cardiogenic shock, recurrent myocardial infarction, stent thrombosis, and stroke.

\section{Statistical analysis}

Continuous variables were presented as the mean and standard deviation or median and interquartile range when the distribution and variance met the appropriate conditions. Categorical variables were presented as percentages. The comparisons between groups of continuous variables were performed by an unpaired t-test or a Mann-Whitney U test (Kruskal-Wallis), and the chisquare test was used to compare the categorical variables. A multivariate logistic regression model was used to determine the association between the type of discrepancy and in-hospital outcomes by controlling for potential confounders. Candidate adjustment factors included age, gender, systolic blood pressure, heart rate, current smoker, hypertension, hemoglobin at admission, eGFR at admission, Killip class, type of acute coronary syndrome, glucose-lowering drug use, and $\beta$-blocker use during hospitalization. The heterogeneity of effects on the in-hospital outcomes across subgroups was estimated using random effects meta-analysis. For data with missing values lower than 15\% (Additional file 1: Table S1), the sequential regression multiple imputation method implemented by IVEware software version 0.2 (Survey Research Center, University of Michigan, Ann Arbor, MI, USA) was used to impute the missing values. All $P$ values were 2 -tailed, and $P<0.05$ was considered statistically significant. Statistical analyses were performed using SPSS 23.0 (SPSS Inc., Chicago, IL) and Stata/IC 15.1.

\section{Results}

Characteristics of patients in the discrepancy group

A total of 7762 patients were included in this study (Additional file 1: Figure S1). The mean age was 64.4 ( \pm 11.6) years, and males accounted for $68.8 \%$ of the study population. The mean hemoglobin level was 135.1 ( \pm 21.3) $\mathrm{g} / \mathrm{L}$, and the mean eGFR was $81.7( \pm 25.4) \mathrm{ml}$ $\min ^{-1}(1.73 \mathrm{~m})^{-2}$. A total of $53.3 \%$ of patients were treated with at least one class of oral glucose-lowering drugs or insulin. The numbers of patients in the consistent group and the discrepancy group were 5490 (70.7\%) and 2272 (29.3\%), respectively. Patients in the discrepancy group were more likely to have lower eGFR (Additional file 1: Figure S2). In the discrepancy group, increased $\mathrm{HbA}_{1 \mathrm{c}}$ but normal FPG accounted for $77.5 \%$ of the discrepancies $(1761 / 2272)$, and increased FPG but normal $\mathrm{HbA}_{1 \mathrm{c}}$ accounted for $22.5 \%$ of the discrepancies $(511 / 2272)$. The baseline characteristics of patients in the increased $\mathrm{HbA}_{1 \mathrm{c}}$ but normal FPG group and increased FPG but normal $\mathrm{HbA}_{1 \mathrm{c}}$ group are shown in 
Table 1. Patients in the increased FPG but normal $\mathrm{HbA}_{1 \mathrm{c}}$ group were more likely to have lower eGFR, higher heart rate, poorer heart function, STEMI and hypertension and to be treated with glucose-lowering agents.
The prevalence of the increased FPG but normal $\mathrm{HbA}_{1 \mathrm{c}}$ discrepancy was higher in patients over 65 years of age, hemoglobin less than $120 \mathrm{~g} / \mathrm{L}$, eGFR less than 60

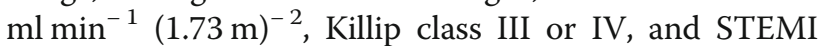

Table 1 Characteristics of patients with discrepancies between $\mathrm{HbA}_{1 c}$ and FPG

\begin{tabular}{|c|c|c|c|}
\hline & $\begin{array}{l}\mathrm{HbA} 1 \mathrm{c} \geq 6.5 \% \text { and } \\
\mathrm{FPG}<7.0 \mathrm{mmol} / \mathrm{L} \\
(n=1761)\end{array}$ & $\begin{array}{l}\mathrm{HbA} 1 \mathrm{c}<6.5 \% \text { and } \\
\mathrm{FPG} \geq 7.0 \mathrm{mmol} / \mathrm{L} \\
(n=511)\end{array}$ & $P$ value \\
\hline Age (years, mean [SD]) & $65.4(11.2)$ & $65.4(10.9)$ & 0.947 \\
\hline Male (n [\%]) & 1184(67.2) & $348(68.1)$ & 0.713 \\
\hline Systolic blood pressure (mmHg, mean [SD]) & $135.0(22.8)$ & $135.0(25.2)$ & 0.895 \\
\hline Diastolic blood pressure (mmHg, median [IQR]) & $78.0(70.0,87.0)$ & $78.0(70.0,89.0)$ & 0.442 \\
\hline Heart rate (bpm. Median [IQR]) & $78.0(68.0,87.0)$ & $80.0(70.0,90.0)$ & $<0.001$ \\
\hline Current smoker (n [\%]) & $508(28.8)$ & 153(29.9) & 0.047 \\
\hline Family history of CHD (n [\%]) & $71(4.0)$ & $21(4.1)$ & 0.937 \\
\hline Hypertension (n [\%]) & $1300(73.8)$ & 403(78.9) & 0.021 \\
\hline Previous acute myocardial infarction (n [\%]) & 214(12.2) & $58(11.4)$ & 0.623 \\
\hline Previous coronary artery bypass grafting (n [\%]) & $16(0.9)$ & $4(0.8)$ & 0.789 \\
\hline Atrial fibrillation history (n [\%]) & $53(3.0)$ & $14(2.7)$ & 0.751 \\
\hline Heart failure history (n [\%]) & $58(3.3)$ & 19(3.7) & 0.640 \\
\hline Cerebrovascular disease history (n [\%]) & 185(10.5) & $57(11.2)$ & 0.675 \\
\hline Peripheral artery disease history (n [\%]) & $31(1.8)$ & 10(2.0) & 0.769 \\
\hline Killip class (n [\%]) & & & 0.289 \\
\hline | or || & 1505(85.5) & $427(83.6)$ & \\
\hline III or IV & $256(14.5)$ & $84(16.4)$ & \\
\hline Types of ACS (n [\%]) & & & $<0.001$ \\
\hline STEMI & $716(40.7)$ & 276(54.0) & \\
\hline NSTE-ACS & 1045(59.3) & 235(46.0) & \\
\hline $\mathrm{HbA}_{1 c}(\%$, mean $[S \mathrm{SD}])$ & $8.2(14.7)$ & $5.8(0.8)$ & $<0.001$ \\
\hline $\mathrm{FPG}(\mathrm{mmol} / \mathrm{L}$, mean $[\mathrm{SD}]) /(\mathrm{mg} / \mathrm{dl}$, mean $[\mathrm{SD}])$ & $5.6(1.2) / 100.8(21.6)$ & $9.5(2.6) / 171.0(46.8)$ & $<0.001$ \\
\hline eGFR $\left(\mathrm{ml} \mathrm{min}{ }^{-1}[1.73 \mathrm{~m}]^{-2}\right.$, mean $\left.[S D]\right)$ & $79.1(25.1)$ & $76.4(27.3)$ & 0.046 \\
\hline Hemoglobin (g/l, mean [SD]) & 132.1(20.4) & 132.4(23.6) & 0.192 \\
\hline Total cholesterol (mmol/L, median [IQR])/(mg/dl, median [IQR]) & $4.3(3.5,5.1) / 166.2(135.3,197.2)$ & $4.3(3.5,5.1) / 166.2(135.3,197.2)$ & 0.721 \\
\hline $\mathrm{HDL}$-cholesterol (mmol/L, median [IQR])/(mg/dl, median [IQR]) & $1.0(0.8,1.2) / 38.7(30.9,46.4)$ & $1.0(0.8,1.2) / 38.7(30.9,46.4)$ & 0.931 \\
\hline LDL-cholesterol (mmol/L, median [IQR])/(mg/dl, median [IQR]) & $2.6(2.0,3.2) / 100.5(77.3,123.7)$ & $2.5(2.0,3.2) / 96.7(77.3,123.7)$ & 0.326 \\
\hline Triglyceride $(\mathrm{mmol} / \mathrm{L}$, median $[\mathrm{IQR}]) /(\mathrm{mg} / \mathrm{dl}$, median $[\mathrm{IQR}])$ & $1.6(1.1,2.4) / 141.8(97.5,212.6)$ & $1.5(1.0,2.3) / 132.9(88.6,203.8)$ & 0.027 \\
\hline Oral glucose-lowering agents or insulin use before admission (n [\%]) & $809(45.9)$ & 288(56.4) & $<0.001$ \\
\hline \multicolumn{4}{|l|}{ Therapy during hospitalization (n [\%]) } \\
\hline Percutaneous coronary intervention & $1170(66.4)$ & $337(65.9)$ & 0.836 \\
\hline Aspirin & 1644(93.4) & 482(94.3) & 0.432 \\
\hline $\mathrm{P}_{2} \mathrm{Y}_{12}$ inhibitors & 1603(91.0) & 473(92.6) & 0.276 \\
\hline Statins & 1653(93.9) & 477(93.3) & 0.669 \\
\hline$\beta$-blockers & $1146(65.1)$ & $291(56.9)$ & 0.001 \\
\hline ACE inhibitor/angiotensin receptor blocker & $917(52.1)$ & $248(48.5)$ & 0.159 \\
\hline Patients with referral (n [\%]) & $587(33.3)$ & 172(33.7) & 0.891 \\
\hline
\end{tabular}

ACE Angiotensin-converting enzyme, ACS Acute coronary syndrome, CHD Coronary heart disease, eGFR Estimated glomerular filtration rate, FPG Fasting plasma glucose, $H b A_{1 c}$ Glycosylated hemoglobin, HDL High-density lipoprotein, IQR Interquartile range, LDL Low-density lipoprotein, NSTE-ACS Non-ST-segment elevation acute coronary syndrome, SD Standard deviation, STEMI ST-segment elevation myocardial infarction 
and who were treated with oral glucose-lowering drugs or insulin (Fig. 1, Additional file 1: Table S2).

\section{Types of discrepancy and in-hospital outcomes}

The comparison of in-hospital outcomes between the increased $\mathrm{HbA}_{1 \mathrm{c}}$ but normal FPG group and the increased FPG but normal $\mathrm{HbA}_{1 \mathrm{c}}$ group is shown in Fig. 2. The rates of all the in-hospital outcomes were higher in the increased FPG but normal $\mathrm{HbA}_{1 \mathrm{c}}$ group than in the increased $\mathrm{HbA}_{1 \mathrm{c}}$ but normal FPG group. A logistic regression model was performed to explore the relationship between the type of discrepancy and in-hospital outcomes, except for death from any cause because of the small event number. In univariate logistic regression analysis, a significantly higher risk of all the in-hospital outcomes was observed in patients with increased FPG but normal $\mathrm{HbA}_{1 \mathrm{c}}$ (Table 2). After adjusting for confounders in the multivariate logistic regression model, patients in the increased FPG but normal $\mathrm{HbA}_{1 \mathrm{c}}$ group had a significant 1.6-fold increased risk of heart failure (OR, 1.62; 95\% CI, 1.08-2.44), a 1.6-fold increased risk of composite cardiovascular death and heart failure (OR, 1.63; 95\% CI, 1.09-2.43), and a 1.6-fold increased risk of composite MACCEs and heart failure (OR, 1.56; $95 \% \mathrm{CI}$, 1.08-2.24) compared to patients in the increased $\mathrm{HbA}_{1 \mathrm{c}}$ group (Table 2). The effect on MACCEs was not significant (OR, 1.49; 95\% CI, 0.85-2.63) (Table 2). Furthermore, to investigate the association between the severe discrepancy and in-hospital outcomes, we used the cut-off values of HbA1c 7.5\% and FPG $8.0 \mathrm{mmol} / \mathrm{L}$. Although the significant $P$ values were not shown in logistic regression analysis, trends that patients in the increased FPG group had higher risks of MACCEs, heart failure, composite cardiovascular dearth and heart failure, and composite MACCEs and heart failure were observed (Additional file 1: Table S3).

Subgroup analysis was performed based on age, sex, medical history, Killip class, hemoglobin, eGFR, type of ACS, glucose-lowering drug use before hospitalization, and $\beta$-blocker use during hospitalization. A higher risk of all the in-hospital outcomes was observed in patients with increased FPG but normal $\mathrm{HbA}_{1 \mathrm{c}}$, which was consistent in all subgroups (all $\mathrm{P}$ for interaction $>0.05$ ), except for the eGFR subgroup for MACCEs (Figs. 3 and 4), which showed that increased FPG but normal $\mathrm{HbA}_{1 \mathrm{c}}$ increased the risk of MACCEs to a greater ex-

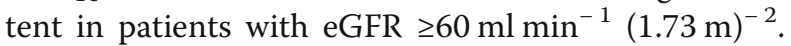

\section{Discussion}

In this study, we investigated the type of discrepancy between $\mathrm{HbA}_{1 \mathrm{c}}$ and FPG in patients with ACS and diabetes. We found that nearly one-third of patients had a discrepancy between $\mathrm{HbA}_{1 \mathrm{c}}$ and FPG. Of the patients with discrepancies, the patients with increased FPG had a higher risk of in-hospital adverse cardiovascular outcomes than those with increased $\mathrm{HbA}_{1 \mathrm{c}}$.

Discrepancies between $\mathrm{HbA}_{1 \mathrm{c}}$ and FPG have been reported by some studies. A study of the risk of

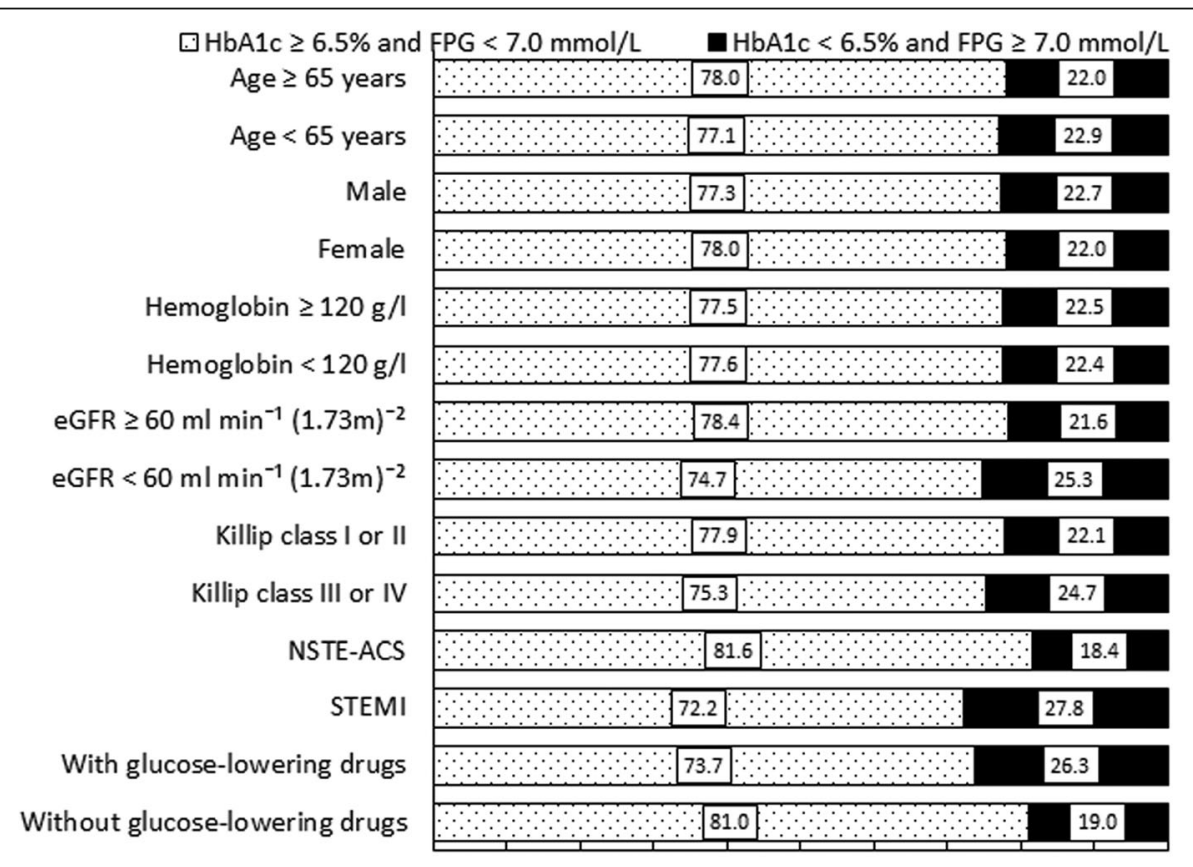

$\begin{array}{llllllllllll}0 \% & 10 \% & 20 \% & 30 \% & 40 \% & 50 \% & 60 \% & 70 \% & 80 \% & 90 \% & 100 \%\end{array}$

Fig. 1 Prevalence of discrepancy in different population. eGFR, estimated glomerular filtration rate; FPG, fasting plasma glucose; $\mathrm{HbA}_{1 \mathrm{c}}$ glycosylated hemoglobin; NSTE-ACS, non-ST-segment elevation acute coronary syndrome; STEMI, ST-segment elevation myocardial infarction 


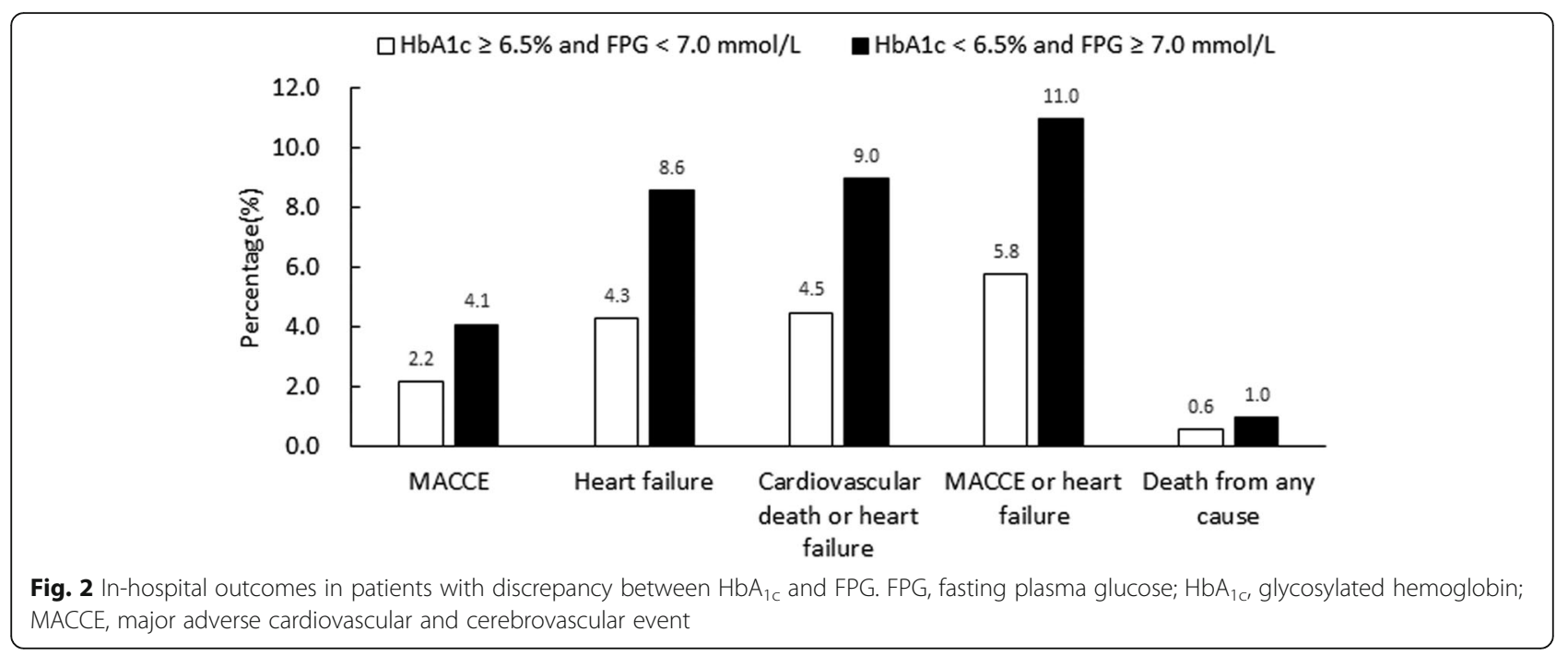

hypertension in patients with prediabetes demonstrated the discrepancy between $\mathrm{HbA}_{1 \mathrm{c}}$ and FPG [20]. A study using data from residents of Yunnan Province, China, showed that a discrepancy between $\mathrm{HbA}_{1 \mathrm{c}}$ and FPG was present in approximately $30 \%$ of participants [21]. In our study, the discrepancy between $\mathrm{HbA}_{1 \mathrm{c}}$ and FPG was also found in patients with ACS and diabetes. We found that the discrepancy group, composed of $77.5 \%$ patients with increased $\mathrm{HbA}_{1 \mathrm{c}}$ but normal FPG and 22.5\% patients with increased FPG but normal $\mathrm{HbA}_{1 \mathrm{c}}$, accounted for $29 \%$ of the total study population. Patients often experience hyperglycemia in the acute phase of many diseases, such as ACS, which is called stress hyperglycemia. $\mathrm{HbA}_{1 \mathrm{c}}$ reflects average glycemia over approximately 3 months, so an increase in $\mathrm{HbA}_{1 \mathrm{c}}$ usually indicates chronic hyperglycemia. We found that patients in the increased FPG but normal $\mathrm{HbA}_{1 \mathrm{c}}$ group were more likely to have lower eGFR and to be treated with glucoselowering agents. A higher proportion of glucoselowering agent use may be related to well-controlled blood glucose and lower $\mathrm{HbA}_{1 \mathrm{c}}$. Furthermore, changes in the metabolism of glucose-lowering drugs, insulin clearance, and the uremic environment in patients with renal function insufficiency may also reduce $\mathrm{HbA}_{1 \mathrm{c}}$ values [22]. From our study, not only was a discrepancy between $\mathrm{HbA}_{1 \mathrm{c}}$ and $\mathrm{FPG}$ be found in patients with chronic kidney disease, but the proportion of the increased FPG group was found to be significantly higher than that of the increased $\mathrm{HbA}_{1 \mathrm{c}}$ group.

There is a strong association between cardiovascular disease, diabetes and chronic kidney disease. People with diabetes and chronic kidney disease have a substantially increased risk of all-cause mortality, cardiovascular mortality, and kidney failure [23, 24]. Furthermore, we analyzed the relationship between the type of discrepancy and in-hospital outcomes. We know that $\mathrm{HbA}_{1 \mathrm{c}}$ and FPG are both closely related to in-hospital outcomes. Most previous studies have shown that increased $\mathrm{HbA}_{1 \mathrm{c}}$ or FPG was significantly associated with poor in-hospital outcomes in patients with ACS and diabetes. An observational study that included 250 patients with ACS found that coronary atherosclerosis was more advanced in patients with $\mathrm{HbA}_{1 \mathrm{c}} \geq 5.7 \%$ than in those with $\mathrm{HbA}_{1 \mathrm{c}}<5.7 \%$ [17]. Goyal et al. [25] conducted a post

Table 2 Logistic regression analysis for in-hospital outcomes in the increased FPG group compared with the increased $\mathrm{HbA}_{1 c}$ group $^{a}$

\begin{tabular}{|c|c|c|c|c|}
\hline & Unadjusted OR (95\% Cl) & $P$ value & $\begin{array}{l}\text { Adjusted OR } \\
(95 \% \mathrm{Cl})^{\mathrm{b}}\end{array}$ & $P$ value \\
\hline MACCE & $1.94(1.13-3.34)$ & 0.016 & $1.52(0.85-2.72)$ & 0.158 \\
\hline Heart failure & $2.09(1.42-3.07)$ & $<0.001$ & $1.63(1.07-2.48)$ & 0.024 \\
\hline Cardiovascular death or heart failure & $2.11(1.44-3.07)$ & $<0.001$ & $1.63(1.08-2.47)$ & 0.021 \\
\hline MACCE or heart failure & $1.98(1.41-2.79)$ & $<0.001$ & $1.57(1.07-2.28)$ & 0.020 \\
\hline
\end{tabular}

${ }^{a}$ A categorized variable to compare the increased FPG group with the increased HbA1c group was used in logistic regression analysis

${ }^{\mathrm{b}}$ ORs were adjusted for age, gender, systolic blood pressure, heart rate, current smoker, hypertension, hemoglobin at admission, eGFR at admission, Killip class, type of acute coronary syndrome, glucose-lowering drug use, and $\beta$-blocker use during hospitalization

FPG Fasting plasma glucose, $\mathrm{HbA}_{1 c}$ Glycosylated hemoglobin, MACCE Major adverse cardiovascular and cerebrovascular event 


\begin{tabular}{|c|c|c|c|c|}
\hline \multirow{2}{*}{$\begin{array}{l}\text { Subgroup } \\
\text { Total }\end{array}$} & \multirow{2}{*}{$\begin{array}{c}\text { Events/total number } \\
59 / 2272\end{array}$} & \multicolumn{2}{|c|}{ Odds Ratio $(95 \%$ a) } & \multirow{2}{*}{$\begin{array}{c}\text { Interaction } \\
P \text { value }\end{array}$} \\
\hline & & 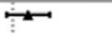 & $1.49(0.85-2.63)$ & \\
\hline Age (years) & & & & 0.106 \\
\hline$\geq 65$ & $43 / 1261$ & $\longrightarrow$ & $1.18(0.58-2.41)$ & \\
\hline$<65$ & 16/1011 & 一 & $3.57(1.14 \cdot 11.12)$ & \\
\hline sex & & & & 0.389 \\
\hline Male & $39 / 1532$ & $\longrightarrow$ & $1.27(0.59-2.71)$ & \\
\hline Female & $20 / 740$ & 一 & $2.18(0.83-5.70)$ & \\
\hline Hypertension & & & & 0.530 \\
\hline Yes & $44 / 1703$ & 一 & $1.43(0.74-2.77)$ & \\
\hline No & $15 / 569$ & & $2.27(0.63-8.16)$ & \\
\hline Hemoglobin $(g / L)$ & & & & 0.787 \\
\hline$\geq 120$ & $42 / 1719$ & $\longrightarrow$ & $1.67(0.82-3.39)$ & \\
\hline$<120$ & $17 / 553$ & 一 & $1.39(0.45-4.28)$ & \\
\hline eGFR (mL/min/1.73m') & & & & 0.012 \\
\hline$\geq 60$ & $30 / 1738$ & $\longmapsto$ & $3.30(1.52-7.16)$ & \\
\hline$<60$ & $29 / 534$ & $\Rightarrow$ & $0.68(0.26-1.77)$ & \\
\hline Killip class & & & & 0.314 \\
\hline 1,11 & $32 / 1932$ & $\longrightarrow$ & $1.32(0.59-2.92)$ & \\
\hline $\mathrm{III,IV}$ & $27 / 340$ & $\longrightarrow$ & $2.46(0.99-6.12)$ & \\
\hline Type of acute coronary syndrome & & & & 0.851 \\
\hline NSTE-ACS & $28 / 1280$ & 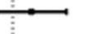 & $1.63(0.65 \cdot 4.05)$ & \\
\hline STEMII & $31 / 992$ & & $1.83(0.83-4.01)$ & \\
\hline Glucose-lowering drug & & & & 0.707 \\
\hline Yes & $31 / 1097$ & $\longrightarrow$ & $1.79(0.83-3.85)$ & \\
\hline No & $28 / 1175$ & & $1.42(0.56-3.62)$ & \\
\hline B-blocker & & & & 0.742 \\
\hline Yes & $25 / 1437$ & $\longrightarrow$ & $1.46(0.57-3.74)$ & \\
\hline No & $34 / 835$ & $\longrightarrow$ & $1.79(0.83-3.87)$ & \\
\hline
\end{tabular}

\section{b. Heart failure}

\begin{tabular}{|c|c|c|c|c|}
\hline \multirow{2}{*}{$\begin{array}{l}\text { Subgroup } \\
\text { Total }\end{array}$} & \multirow{2}{*}{$\begin{array}{c}\text { Events/total number } \\
120 / 2272\end{array}$} & \multicolumn{2}{|c|}{ Odds Ratio (95\% Cl) } & \multirow{2}{*}{$\begin{array}{c}\text { Interaction } \\
\boldsymbol{P} \text { value }\end{array}$} \\
\hline & & $-\infty$ & $1.62(1.08-2.44)$ & \\
\hline Age (years) & & & & 0.516 \\
\hline 265 & $91 / 1261$ & 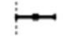 & $1.63(1.00-2.67)$ & \\
\hline$<65$ & 29/1011 & & $2.27(0.95-5.43)$ & \\
\hline Sex & & & & 0.508 \\
\hline Male & $67 / 1532$ & & $1.41(0.80-2.51)$ & \\
\hline Female & $53 / 740$ & $\bullet$ & $1.89(0.98-3.61)$ & \\
\hline Hypertension & & & & 0.153 \\
\hline Yes & $92 / 1703$ & & $1.38(0.85-2.25)$ & \\
\hline No & $28 / 569$ & & $2.88(1.19-6.97)$ & \\
\hline Hemoglobin $(g / L)$ & & & & 0.520 \\
\hline$\geq 120$ & $68 / 1719$ & & $1.73(0.99 \cdot 3.00)$ & \\
\hline$<120$ & $52 / 553$ & $\vec{x}$ & $1.29(0.64-2.61)$ & \\
\hline eGFR (mL/min/1.73m') & & & & 0.791 \\
\hline$\geq 60$ & $62 / 1738$ & & $1.75(0.98-3.14)$ & \\
\hline$<60$ & $58 / 534$ & & $1.56(0.84-2.91)$ & \\
\hline Killip class & & & & 0.946 \\
\hline I, II & $68 / 1932$ & & $1.63(0.95-2.81)$ & \\
\hline III, IV & $52 / 340$ & & $1.68(0.84-3.36)$ & \\
\hline Type of acute coronary syndrome & & & & 0.614 \\
\hline NSTE-ACS & $56 / 1280$ & 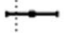 & $1.49(0.78-2.83)$ & \\
\hline STEMI & $64 / 992$ & $\longrightarrow$ & $1.86(1.05-3.28)$ & \\
\hline Glucose-lowering drug & & & & 0.870 \\
\hline Yes & $68 / 1097$ & - & $1.59(0.92-2.75)$ & \\
\hline No & $52 / 1175$ & $\longrightarrow$ & $1.71(0.87-3.35)$ & \\
\hline B-blocker & & & & 0.644 \\
\hline Yes & $61 / 1437$ & & $1.41(0.77-2.59)$ & \\
\hline No & $59 / 835$ & $\longleftrightarrow$ & $1.73(0.93-3.22)$ & \\
\hline
\end{tabular}

Fig. 3 (See legend on next page.) 
(See figure on previous page.)

Fig. 3 Subgroup analysis for association between the type of discrepancy and in-hospital outcomes*. ${ }^{*}$ A categorized variable to compare the increased FPG group with the increased $\mathrm{HbA}_{1 c}$ group was used in logistic regression analysis. ORs were adjusted for age, gender, systolic blood pressure, heart rate, current smoker, hypertension, hemoglobin at admission, eGFR at admission, Killip class, type of acute coronary syndrome, and glucose-lowering drug use. Panel a shows the effect of the increased FPG group on MACCE compared with increased HbA $1 c$ group. Panel $\mathbf{b}$ shows the effect of the increased FPG group on heart failure compared with increased $\mathrm{HbA}_{1 c}$ group. eGFR, estimated glomerular filtration rate; FPG, fasting plasma glucose; $\mathrm{HbA}_{1 c}$, glycosylated hemoglobin; MACCE, major adverse cardiovascular and cerebrovascular event; NSTE-ACS, nonST-segment elevation acute coronary syndrome; STEMI, ST-segment elevation myocardial infarction

hoc analysis including two randomized controlled trials of acute myocardial infarction with ST-segment elevation, involving 30,536 subjects with diabetes history, and showed that patients with in-hospital glucose $\geq 144 \mathrm{mg} /$ $\mathrm{dL}$ had a very high risk of death. A retrospective cohort study of 768 patients with post-myocardial infarction was conducted, and the results showed that presence of impaired glucose tolerance and newly diagnosed diabetes mellitus is associated with increased incidence of adverse outcomes [26]. Kiviniemi et al. conducted a prospective cohort study that included patients with coronary artery disease, and the results showed that the adverse outcomes in patients with impaired glucose tolerance or impaired fasting glucose does not differ from those values in patients with normal glycemic status, while patients with type 2 diabetes had a higher risk of adverse outcomes [27]. Contradictory results between this and previous studies may not be fully explained, but the differences in research population and medical treatment may play a role. However, in clinical practice, some conditions, such as acute stress, renal dysfunction, and anemia, can cause uncertainty in the measured values of FPG and $\mathrm{HbA}_{1 \mathrm{c}}$ and the discrepancy between them. Until now, the association of in-hospital outcomes with the discrepancy between $\mathrm{HbA}_{1 \mathrm{c}}$ and FPG in patients with ACS and diabetes has not been clear. There are few studies focusing on this issue. From our study, we can conclude that patients in the increased FPG group, who were more likely to have a higher heart rate, poorer heart function, and higher incidence rates of STEMI and hypertension, had a higher risk of in-hospital cardiovascular adverse outcomes than those with increased $\mathrm{HbA}_{1 \mathrm{c}}$. Stress hyperglycemia, which is a reflection of high free fatty acids, insulin resistance, and steroid hormones, affects the course of the disease in an adverse way [28]. From another study, we learned that the level of stress hyperglycemia often correlates with the severity of disease and can predict mortality [29]. In our study, we also found that patients with severe clinical conditions, such as a higher heart rate and poorer heart function, were more likely to have increased FPG. As a result, stress hyperglycemia may have a greater adverse effect on patients with ACS and diabetes than chronic hyperglycemia.
The findings of this study may have some important implications for clinical practice. The $\mathrm{HbA}_{1 \mathrm{c}}$ test is a major tool for assessing glycemic control and has strong predictive value for diabetes complications [30]. Chronic hyperglycemia is an important risk factor for cardiovascular disease and mortality [24], although the variability in $\mathrm{HbA}_{1 \mathrm{c}}$ in patients with renal insufficiency should be considered. However, in patients with ACS and diabetes, increased FPG may be associated with a higher risk of adverse in-hospital outcomes, even if $\mathrm{HbA}_{1 \mathrm{c}}$ is well controlled. These patients, especially those with renal insufficiency, should be given more attention and closer monitoring in clinical practice.

The major strength of our study is that it is based on a nationally representative registry and is aimed at investigating the discrepancy between $\mathrm{HbA}_{1 \mathrm{c}}$ and FPG and the influence of the discrepancies on the in-hospital outcomes of patients with ACS and diabetes, which has rarely been reported until now. Our study also has certain limitations. First, all-cause mortality was not included in the logistic regression analysis because of very limited events. Second, we could not collect all information related to glucose metabolism in this real-world study of ACS patients based on medical records, thus contributing to some residual confounding from unmeasured confounders. Last, fasting status, blood sample collection and testing methods were difficult to unify, as this was a real-world multicenter study.

\section{Conclusions}

In summary, our study showed that the discrepancy between $\mathrm{HbA}_{1 \mathrm{c}}$ and FPG accounts for nearly 30\% of discrepancies among patients with ACS and diabetes. Patients with an increased level of FPG had a higher risk of in-hospital cardiovascular adverse outcomes than those with an increased level of $\mathrm{HbA}_{1 \mathrm{c}}$. This result may indicate that when $\mathrm{HbA}_{1 \mathrm{c}}$ and FPG are inconsistent in patients with ACS and diabetes, the increased FPG that may be caused by stress hyperglycemia may have a more substantial adverse effect than increased $\mathrm{HbA}_{1 \mathrm{c}}$, which may be caused by chronic hyperglycemia. These highrisk patients should be given more attention and closer monitoring in clinical practice. 


\begin{tabular}{|c|c|c|c|c|}
\hline \multirow{2}{*}{$\begin{array}{l}\text { Subgroup } \\
\text { Total }\end{array}$} & \multirow{2}{*}{$\begin{array}{c}\text { Events/total number } \\
125 / 2272\end{array}$} & \multicolumn{2}{|c|}{ Odds Ratio (95\% a) } & \multirow{2}{*}{$\begin{array}{c}\text { Interaction } \\
\boldsymbol{P} \text { value }\end{array}$} \\
\hline & & $\approx$ & $1.63(1.09-2.43)$ & \\
\hline Age (years) & & & & 0.672 \\
\hline 265 & $95 / 1261$ & $\rightarrow$ & $1.68(1.04-2.73)$ & \\
\hline$<65$ & 30/1011 & $\longrightarrow$ & $2.08(0.88-4.94)$ & \\
\hline sex & & & & 0.634 \\
\hline Male & $71 / 1532$ & 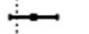 & $1.48(0.85 \cdot 2.58)$ & \\
\hline Female & $54 / 740$ & 一 & $1.82(0.95-3.46)$ & \\
\hline Hypertension & & & & 0.111 \\
\hline Yes & $95 / 1703$ & - & $1.38(0.86-2.23)$ & \\
\hline No & $30 / 569$ & 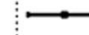 & $3.06(1.30-7.21)$ & \\
\hline Hemoglobin $(g / L)$ & & & & 0.273 \\
\hline$\geq 120$ & $70 / 1719$ & $\rightarrow$ & $1.91(1.11-3.28)$ & \\
\hline$<120$ & $55 / 553$ & — & $1.17(0.59-2.34)$ & \\
\hline eGFR (mL/min/1.73m') & & & & 0.536 \\
\hline 260 & $65 / 1738$ & $\longrightarrow$ & $1.89(1.07-3.33)$ & \\
\hline$<60$ & $60 / 534$ & - & $1.45(0.78-2.68)$ & \\
\hline Killip class & & & & 0.702 \\
\hline 1, I1 & $72 / 1932$ & $\infty$ & $1.57(0.92-2.67)$ & \\
\hline $\mathrm{III, \textrm {N }}$ & $53 / 340$ & $\longrightarrow$ & $1.86(0.94-3.69)$ & \\
\hline Type of acute coronary syndrome & & & & 0.500 \\
\hline NSTE-ACS & $57 / 1280$ & $\longrightarrow$ & $1.44(0.76-2.74)$ & \\
\hline STEMI & $68 / 992$ & $\rightarrow$ & $1.93(1.10-3.36)$ & \\
\hline Glucose-lowering drug & & & & 0.978 \\
\hline Yes & $72 / 1097$ & $\rightarrow$ & $1.65(0.97-2.81)$ & \\
\hline No & $53 / 1175$ & $\longrightarrow$ & $1.63(0.83-3.18)$ & \\
\hline B-blocker & & & & 0.638 \\
\hline Yes & 61/1437 & 一 & $1.41(0.77-2.59)$ & \\
\hline No & $64 / 835$ & $\square$ & $1.73(0.95-3.15)$ & \\
\hline
\end{tabular}

d. The composite of MACCE and heart failure

\begin{tabular}{|c|c|c|c|c|}
\hline Subgroup & Events/total number & Odds R & $\%$ a) & Interaction \\
\hline Total & $159 / 2272$ & & $1.56(1.08-2.24)$ & \\
\hline Age (years) & & & & 0.168 \\
\hline 265 & $117 / 1261$ & - & $1.43(0.91-2.24)$ & \\
\hline$<65$ & $42 / 1011$ & $\longrightarrow$ & $2.61(1.26-5.40)$ & \\
\hline Sex & & & & 0.418 \\
\hline Male & $95 / 1532$ & 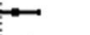 & $1.37(0.83-2.27)$ & \\
\hline Female & $64 / 740$ & & $1.89(1.04-3.41)$ & \\
\hline Hypertension & & & & 0.110 \\
\hline Yes & 122/1703 & 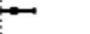 & $1.34(0.87-2.06)$ & \\
\hline No & $37 / 569$ & $\infty$ & $2.82(1.26-6.28)$ & \\
\hline Hemoglobin $(g / L)$ & & & & 0.235 \\
\hline$\geq 120$ & $98 / 1719$ & • & $1.79(1.12-2.88)$ & \\
\hline$<120$ & $61 / 553$ & & $1.09(0.56-2.13)$ & \\
\hline eGFR (mL/min/1.73m') & & & & 0.227 \\
\hline 260 & $83 / 1738$ & 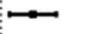 & $1.99(1.21-3.29)$ & \\
\hline$<60$ & $76 / 534$ & & $1.24(0.69-2.21)$ & \\
\hline Killip class & & & & 0.817 \\
\hline 1,11 & 90/1932 & $\because$ & $1.69(1.05-2.71)$ & \\
\hline $\mathrm{III,N}$ & $69 / 340$ & & $1.54(0.82-2.89)$ & \\
\hline Type of acute coronary syndrome & & & & 0.555 \\
\hline NSTE-ACS & $74 / 1280$ & & $1.45(0.80-2.60)$ & \\
\hline STEMI & $85 / 992$ & & $1.83(1.11-3.02)$ & \\
\hline Glucose-lowering drug & & & & 0.824 \\
\hline Yes & $87 / 1097$ & $\boldsymbol{-}$ & $1.68(1.03-2.74)$ & \\
\hline No & $72 / 1175$ & & $1.54(0.85-2.78)$ & \\
\hline B-blocker & & & & 0.550 \\
\hline Yes & $76 / 1437$ & & $1.36(0.78-2.37)$ & \\
\hline No & $83 / 835$ & $\rightarrow$ & $1.72(1.01-2.93)$ & \\
\hline
\end{tabular}

Fig. 4 Panel $c$ shows the effect of the increased FPG group on the composite of cardiovascular death and heart failure compared with the increased $\mathrm{HbA}_{1 c}$ group. Panel $d$ shows the effect of the increased FPG group on the composite of MACCE and heart failure compared with the increased $\mathrm{HbA} \mathrm{A}_{1 c}$ group. eGFR, estimated glomerular filtration rate; FPG, fasting plasma glucose; $\mathrm{HbA}_{1,}$ glycosylated hemoglobin; MACCE, major adverse cardiovascular and cerebrovascular event; NSTE-ACS, non-ST-segment elevation acute coronary syndrome; STEMI, ST-segment elevation myocardial infarction 


\section{Supplementary information}

Supplementary information accompanies this paper at https://doi.org/10. 1186/s12872-020-01662-3.

Additional file 1 : Table S1. Variables with missing values and missing rates for total population in the CCC - ACS project $(N=92,509)$. Table S2. Prevalence of discrepancies in different populations. Table S3. Logistic regression analysis for in-hospital outcomes in the increased FPG group compared with the increased $\mathrm{HbA} 1 \mathrm{c}$ group. Table S4. Investigators of the CCC-ACS project. Figure S1. Flow chart of patients considered for inclusion. Figure S2. Association between discrepancy and renal function.

\section{Abbreviations}

ACS: Acute coronary syndrome; CCC-ACS: Improving Care for Cardiovascular Disease in China - acute coronary syndrome; eGFR: Estimated glomerular filtration rate; FPG: Fasting plasma glucose; $\mathrm{HbA}_{1}$ : Glycosylated hemoglobin; MACCES: Major adverse cardiovascular and cerebrovascular events; STEMI: STsegment elevation myocardial infarction

\section{Acknowledgments}

We acknowledge all participating hospitals for their contributions to the CCC-ACS project (Additional file 1: Table S4). We would like to thank AJE (www.aje.cn) for English language editing.

\section{Authors' contributions}

HC, NY, DZ, CSM and JL designed the study; NY, LJY, GQW, WJB, FBX, YCH, JL and NY cleaned up the data; NY and LJY analyzed the data; NY and HC wrote the manuscript. All authors reviewed and edited the manuscript. All authors read and approved the final manuscript.

\section{Funding}

The CCC-ACS project is a collaborative program of the American Heart Association and the Chinese Society of Cardiology. The American Heart Association was funded by Pfizer and AstraZeneca for the quality improvement initiative through an independent grant for learning and change. The funding bodies had no role in the design of this study; in the collection, analysis, and interpretation of data; or in writing the manuscript.

\section{Availability of data and materials}

The datasets used and analyzed during the current study are available from the principal investigator of CCC-ACS on reasonable request.

\section{Ethics approval and consent to participate}

Institutional review board approval was granted for the aggregate data set for research and quality improvement by the Ethics Committee of Beijing Anzhen Hospital, Capital Medical University. As this was a large populationbased study, approval from the Ethics Committee of Beijing Anzhen Hospital, Capital Medical University, included a waiver of informed consent.

\section{Consent for publication}

Not applicable.

\section{Competing interests}

The authors declare that they have no competing interests.

\section{Author details}

${ }^{1}$ Renal Division, Beijing Anzhen Hospital, Capital Medical University, Beijing, China. ${ }^{2}$ Department of Cardiology, Beijing Anzhen Hospital, Capital Medical University, Beijing, China. ${ }^{3}$ Department of Epidemiology, Beijing Anzhen Hospital, Capital Medical University, Beijing Institute of Heart, Lung and Blood Vessel Diseases, No. 2 Anzhen Street, Chao yang District, Beijing 100029, PR China.
Received: 18 May 2020 Accepted: 9 August 2020

Published online: 20 August 2020

\section{References}

1. Zhao D, Liu J, Wang M, Zhang X, Zhou M. Epidemiology of cardiovascular disease in China: current features and implications. Nat Rev Cardiol. 2019;16: 203-12. https://doi.org/10.1038/s41569-018-0119-4.

2. Lenzen M, Ryden L, Ohrvik J, Bartnik M, Malmberg K, Scholte Op Reimer W, et al. Diabetes known or newly detected, but not impaired glucose regulation, has a negative influence on 1-year outcome in patients with coronary artery disease: a report from the Euro Heart Survey on diabetes and the heart. Eur Heart J. 2006;27:2969-74. https://doi.org/10.1093/ eurheartj/ehl363.

3. Figueiredo VN, Godoi FC, Martins NS, Quinaglia e Silva JC, Nadruz W Jr, Coelho OR, et al. Diabetes mellitus unawareness is a strong determinant of mortality in patients manifesting myocardial infarction. Curr Med Res Opin. 2013;29:1423-7. https://doi.org/10.1185/03007995.2013.832186.

4. Aggarwal B, Shah GK, Randhawa M, Ellis SG, Lincoff AM, Menon V. Utility of Glycated hemoglobin for assessment of glucose metabolism in patients with ST-segment elevation myocardial infarction. Am J Cardiol. 2016;117: 749-53. https://doi.org/10.1016/j.amjcard.2015.11.060.

5. Rawshani A, Rawshani A, Franzen S, Sattar N, Eliasson B, Svensson AM, et al. Risk factors, mortality, and cardiovascular outcomes in patients with type 2 diabetes. N Engl J Med. 2018;379:633-44. https://doi.org/10.1056/ NEJMoa1800256.

6. Zhou M, Liu J, Hao Y, Liu J, Huo Y, Smith SC Jr, et al. Prevalence and inhospital outcomes of diabetes among patients with acute coronary syndrome in China: findings from the improving Care for Cardiovascular Disease in China-acute coronary syndrome project. Cardiovasc Diabetol. 2018;17:147. https://doi.org/10.1186/s12933-018-0793-X.

7. Bjarnason TA, Hafthorsson SO, Kristinsdottir LB, Oskarsdottir ES, Johnsen A Andersen $\mathrm{K}$. The prognostic effect of known and newly detected type 2 diabetes in patients with acute coronary syndrome. Eur Heart J Acute Cardiovasc Care. 2019;2048872619849925. https://doi.org/10.1177/ 2048872619849925

8. Nystrom T, Sartipy U, Contardi A, Lind M, Bellocco R, Eliasson B, et al. Glycated hemoglobin A1c levels in type 1 diabetes mellitus and outcomes after myocardial infarction. Circulation. 2019;139:2380-2. https://doi.org/10. 1161/CIRCULATIONAHA.118.039223.

9. American Diabetes Association. Diagnosis and classification of diabetes mellitus. Diabetes Care. 2013;36:S67-74. https://doi.org/10.2337/dc13-S067.

10. Dziewierz A, Giszterowicz D, Siudak Z, Rakowski T, Dubiel JS, Dudek D. Admission glucose level and in-hospital outcomes in diabetic and nondiabetic patients with acute myocardial infarction. Clin Res Cardiol. 2010;99: 715-21. https://doi.org/10.1007/s00392-010-0175-1.

11. Li DB, Hua Q, Guo J, Li HW, Chen H, Zhao SM. Admission glucose level and in-hospital outcomes in diabetic and non-diabetic patients with STelevation acute myocardial infarction. Intern Med. 2011:50:2471-5. https:// doi.org/10.2169/internalmedicine.50.5750.

12. Sanjuán R, Núñez J, Luisa Blasco M, Miñana G, Martínez-Maicas H, Carbonell $\mathrm{N}$, et al. Prognostic Implications of Stress Hyperglycemia in Acute ST Elevation Myocardial Infarction. Prospective Observational Study. Rev Esp Cardiol. 2011;64:201-7. https://doi.org/10.1016/j.rec.2010.08.005.

13. Tsai JP, Tian J, Wang WY, Ng AC. Glycated hemoglobin vs fasting plasma glucose as a predictor of left ventricular dysfunction after ST-elevation myocardial infarction. Can J Cardiol. 2015;31:44-9. https://doi.org/10.1016/j. cjca.2014.10.029.

14. Liang H, Guo YC, Chen LM, Li M, Han WZ, Zhang X, et al. Relationship between fasting glucose levels and in-hospital mortality in Chinese patients with acute myocardial infarction and diabetes mellitus: a retrospective cohort study. BMC Cardiovasc Disord. 2016;16:156. https://doi.org/10.1186/s12872-016-0331-2.

15. Farhan S, Clare RM, Jarai R, Giugliano RP, Lokhnygina Y, Harrington RA, et al. Fasting glucose, NT-proBNP, treatment with eptifibatide, and outcomes in non-ST-segment elevation acute coronary syndromes: an analysis from EARLY ACS. Int J Cardiol. 2017;232:264-70. https://doi.org/10.1016/j.jijcard.2017.01.007.

16. Zhao S, Murugiah K, Li N, Li X, Xu ZH, Li J, et al. Admission Glucose and Inhospital Mortality after Acute Myocardial Infarction in Patients with or without Diabetes: A Cross-sectional Study. Chin Med J (Engl). 2017:130:76775. https://doi.org/10.4103/0366-6999.202733.

17. Acar B, Ozeke O, Karakurt M, Ozen Y, Ozbay MB, Unal S, et al. Association of Prediabetes with Higher Coronary Atherosclerotic Burden among Patients 
with First Diagnosed Acute Coronary Syndrome. Angiology. 2019;70:174-80. https://doi.org/10.1177/0003319718772420.

18. Hao Y, Liu J, Liu J, Smith SC Jr, Huo Y, Fonarow GC, et al. Rationale and design of the improving Care for Cardiovascular Disease in China (CCC) project: a national effort to prompt quality enhancement for acute coronary syndrome. Am Heart J. 2016;179:107-15. https://doi.org/10.1016/j.ahj.2016.06.005.

19. Levey ASSL, Schmid CH, Zhang YL, Castro AF 3rd, Feldman HI, Kusek JW, Eggers P, Van Lente F, Greene T, Coresh J. CKD-EPI (chronic kidney disease epidemiology collaboration). A new equation to estimate glomerular filtration rate. Ann Intern Med. 2009;150:604-12.

20. Geva M, Shlomai G, Berkovich A, Maor E, Leibowitz A, Tenenbaum A, et al. The association between fasting plasma glucose and glycated hemoglobin in the prediabetes range and future development of hypertension. Cardiovasc Diabetol. 2019;18:53. https://doi.org/10.1186/s12933-019-0859-4.

21. Feng L, Nian S, Zhao Y, Bai X, Luo F, Luo X, et al. Higher HbA1C and/or glucose levels alter the association patterns between glycated hemoglobin and fasting glucose levels. Diabetes Res Clin Pract. 2018;142:353-62. https:// doi.org/10.1016/j.diabres.2018.06.011.

22. Kuo IC, Lin HY, Niu SW, Hwang DY, Lee JJ, Tsai JC, et al. Glycated hemoglobin and outcomes in patients with advanced diabetic chronic kidney disease. Sci Rep. 2016;6:20028. https://doi.org/10.1038/srep20028.

23. Fox CS, Matsushita K, Woodward M, Bilo HJG, Chalmers J, Heerspink HJL, et al. Associations of kidney disease measures with mortality and end-stage renal disease in individuals with and without diabetes: a meta-analysis. Lancet. 2012;380:1662-73. https://doi.org/10.1016/s0140-6736(12)61350-6.

24. American Diabetes Association. 10. Cardiovascular Disease and Risk Management: Standards of Medical Care in Diabetes-2020. Diabetes Care. 2020:43:S111-34. https://doi.org/10.2337/dc20-S010.

25. Goyal A, Mehta SR, Gerstein HC, Diaz R, Afzal R, Xavier D, et al. Glucose levels compared with diabetes history in the risk assessment of patients with acute myocardial infarction. Am Heart J. 2009;157:763-70. https://doi. org/10.1016/j.ahj.2008.12.007.

26. George A, Bhatia RT, Buchanan GL, Whiteside A, Moisey RS, Beer SF, et al. Impaired glucose tolerance or newly diagnosed diabetes mellitus diagnosed during admission adversely affects prognosis after myocardial infarction: an observational study. PLoS One. 2015;10:e0142045. https://doi. org/10.1371/journal.pone.0142045.

27. Kiviniemi AM, Lepojarvi ES, Tulppo MP, Piira OP, Kentta TV, Perkiomaki JS, et al. Prediabetes and risk for cardiac death among patients with coronary artery disease: the ARTEMIS study. Diabetes Care. 2019;42:1319-25. https:// doi.org/10.2337/dc18-2549.

28. Görmeli Kurt N. Relation of stress hyperglycemia to mortality in acute myocardial infarction patients. Eurasian J Med Oncol. 2018;2:138-41. https:// doi.org/10.14744/ejmo.2018.49469.

29. Cheung NW, Wong KYC, Kovoor P, McLean M. Stress hyperglycemia: a prospective study examining the relationship between glucose, cortisol and diabetes in myocardial infarction. J Diabetes Complicat. 2019;33:329-34. https://doi.org/10.1016/j.jdiacomp.2018.12.015.

30. American Diabetes Association. 6. Glycemic Targets: standards of medical care in diabetes-2020. Diabetes Care. 2020;43:S66-76. https://doi.org/10. 2337/dc20-5006

\section{Publisher's Note}

Springer Nature remains neutral with regard to jurisdictional claims in published maps and institutional affiliations.

Ready to submit your research? Choose BMC and benefit from:

- fast, convenient online submission

- thorough peer review by experienced researchers in your field

- rapid publication on acceptance

- support for research data, including large and complex data types

- gold Open Access which fosters wider collaboration and increased citations

- maximum visibility for your research: over $100 \mathrm{M}$ website views per year

At BMC, research is always in progress.

Learn more biomedcentral.com/submissions 